\title{
Students' Perception Towards National Examination 2017: Computer-Based Test or Paper-Based Test
}

\author{
Dr. Jamiludin \\ M. Hum., Associate Professor, \\ History Education Department, Halu Oleo University \\ Dr. Darnawati \\ M. Pd., Senior Lecturer, \\ History Education Department, Halu Oleo University \\ Waode Ade Sarasmita Uke \\ S.Pd., M. Pd., Lecturer, \\ English Education Department, Halu Oleo University
}

Doi: $10.2478 / \mathrm{mjss}-2018-0083$

\section{Abstract}

Today, technological development has given a new lease of life in language learning and teaching field. Particularly in terms of evaluation, some schools in Indonesia conduct national examination using computer-based test. Traditionally, testing in a class involves paper-based test which is familiar to students. A substantial number of studies have been conducted to compare both of the tests. The researcher investigated what activities were performed by the students throughout the tests, what kind of multiple choice tests the students prefer to do, and what the positive and negative side of those tests. This study presents a wonder share quiz creator (WSQC) program to facilitate the teachers to design a test. The data was collected by questionnaire, interview, observation, and quiz. In this study, the authors concluded that students in senior high school of Kendari prefer paper-based test for national examination.

Keywords: National Examination, Computer-Based Test, Paper-Based Test

\section{Introduction}

National examination is an evaluation type which is conducted at schools and tailored to national achievement standard. It is held at the end of the learning process. It is used to acquire, analyze, and interpret the students' learning process and their learning outcomes systematically and sustainably. The results of the examination in a school will provide information on the success rate of students achieving the learning objectives.

The development of information and communication technology (ICT) appears to help the teachers to evaluate the students. Moreover, the government asks some schools to conduct national examination by using computer-based testing (CBT). The popularity of CBT can overcome the weaknesses of the paper-based test (PBT). The use of CBT is possible to assess more students in less time because of the computer.

Some schools in Java, Indonesia have been conducting CBT since 2015. They can conduct it because the schools have better facilities, but the case in other provinces in Indonesia might be very different. In Kendari, Southeast Sulawesi - Indonesia, for instance, most of schools still use paper-based test (PBT) for the national examination included SMAN 1 Kendari. It is because of the unstable internet network connection and lack of supporting facilities. Besides, the students are not familiar enough with CBT to do the examination. CBT is somehow quite new thing for them.

Responding to the above problems, there are some ways that the authors believe that those 
might address the problems. First, the government should provide computers and internet connection for the schools. Second, the teachers should have positive attitude towards technology. Therefore, the students might feel the same way and at the end they can master using the computer. Third, the teachers should elevate their students 'motivation. Hence, the students might explore CBT themselves. Zhao (2016) argues that teachers should not only focus on the students' knowledge but also try to motivate them. There are some ways to do this as like to educate the students persistently, to summarize important points before a class is over and to review the material regularly, to give more encouragement, and to give feedback, and to provide inspiring and attracting materials by using multimedia or technology.

Heafner (2004, p. 46) states that, "students enjoyed working on the project with technology because they viewed technology as more engaging and entertaining. All students reported enjoyment in the task because technology made their work easier and more fun to do". Zhao and Heafner have the same perspective that teaching students using technology is one of the ways to motivate the students including the use of computers, internet, mobile phone, projector and so on. Besides, O'Donoghue, Singh et al. (2004) argue that students can get benefit from the use of technology and multimedia which can help them to enhance their learning process. Moreover, DeSouza and Fleming (2003) argue that students can access some material and supplementary readings from website using technology. Likewise, technology can provide an alternative method of assessment.

Finally, another way to help students get used to CBT is the students have to familiarize themselves with it. The teacher might use online quiz to assess the students. Being through this kind of quiz, indirectly, it will make the students get familiar with a test using computer. One of online quiz applications is a wonder share quiz creator (WSQC) which can be used to design various tests, such as multiple choices, essay, true or false, and so forth. This application can give immediate feedback after doing the test. The students also can know how many correct numbers they got. Bates (2005, p. 143) states that, "tests may require the student to click on multiple choice answer options on the screen. The computer will respond with the words 'correct' or 'wrong', or sounds such as cheering or boos." The teachers have to give the students some quizzes regularly, and practice them; hence they are familiar with the test. Coffman (2009, p. 129) comments that, "technology tools are best integrated when they are student-driven". It can be concluded that the students have to explore the technology using their existing knowledge about technology, for example, they may explore and analyze CBT themselves apart from teaching and learning hours.

In relation to the implementation of CBT, some advantages and drawbacks of CBT might be spelled out. The application of CBT in national examination is believed to increase students' motivation, improve the accuracy of data collection, and report the test final results in no time. However, CBT implementation has to rely on the internet connection. If it is unstable, the testing process cannot be undertaken. Besides, because of the final result will come out as soon as the test is finished, some students might get worried and nervous. If they fail, they will be very disappointed.

As the opposite idea of CBT, paper-based test (PBT) has its own advantage and disadvantage as well. PBT has been very popular among the students, so the students are familiar with it because it is easy to handle. Nevertheless, sometimes the quality of pictures and words on the paper is disappointing because of the photocopy result. Cheating among the students and taking much time to know the final result of the test are some of unavoidable drawbacks as well.

Many researchers have conducted similar studies. Al-Amri (2007, p. 108), shows, "more than half of the participants developed a positive attitude towards the majority of CBT features. For instance, it was easier for $51 \%$ of the subjects to navigate through the passages on computer than on paper, and $43 \%$ found it easier to read the test items on the computer than on paper". Besides, overall sample teachers have positive attitude towards computer based examination system but in some situations they preferred paper-based test (Jamil, H. et al. 2012). Ghaderi (2014) also states that CBT has grown in popularity and will become a delivering test in the future. Candrlic, Katic et al. (2014, p. 779 ) conclude, "online tests can replace traditional paper-based tests for students' assessment, but particular attention should be paid to its composition. Therefore, we propose the following model for transition to the online testing". Based on the previous studies, the aim of this study is to know the students' perception towards National Examination that will be conducted in 2017: using computer-based test or paper-based test. 


\subsection{Research Questions}

The proposed study is guided by the following questions:

1. What is the students' perception toward CBT and PBT?

2. What are the positive and negative sides of CBT and PBT?

\section{Methods}

\subsection{Design of Research}

The design of this research was a survey design. It had 34 senior high school students in the third grade which were chosen using purposive random sampling. To obtain the answer to the research questions, a close-ended questionnaire with twenty questions which was adapted from Tseng (2010) was distributed to the students. The questionnaire was divided into two parts. The first part included questions regarding the students' perception towards paper-based test and computerbased test and the second part included questions regarding the student's perception towards hypertext. Additionally, the interview was used as supplementary data. It was used to gain in-depth data which could not be probed through questionnaire.

\subsection{Procedures Data Collection}

The participants were asked to do English multiple choices questions not only using paper-based test but also using the computer-based test. Then, the students filled out the questionnaires. Further, they also would have 15 minutes personal interview. The researchers involved ten students randomly.

\subsection{Technique of Data analysis}

To analyze the data, the researchers used SPSS (Statistical Package for the Social Sciences) 15 Program for Windows. Paired Sample Test analysis was used as well.

\section{Results and Discussion}

This part spells out the answer of the research questions based on the collected data.

\subsection{Students' Perception toward Computer-Based Test versus Paper-Based Test}

After asking the students to do a computer-based and paper-based test, they performed different reactions. Doing CBT was the first experience for them. They should have prior knowledge about how to operate computer. They need a mouse, keyboard, computer, and internet connection. Some of the students were quite surprised when they obtained their final score since they did not pass the test.

Meanwhile, when the students did the exam using PBT, although they are familiar with such test, they still cheated with their friends. In fact, it was easy for them to ask their friends because the paper could be forth and back easily.

Table 1: Pair Sample Test Part I. Students Perception of Paper-Based Test and Computer-Based Test

\begin{tabular}{|c|c|l|c|}
\hline Pair & Q & Statement & Mean \\
\hline \multirow{2}{*}{ Pair 1 } & Q1 & Paper-based test is more difficult to read than computer-based test. & 3.4242 \\
\cline { 2 - 4 } & Q2 & The computer-based test is more difficult to read than paper-based test. & 2.4242 \\
\hline Pair 2 & Q4 & $\begin{array}{l}\text { In the paper-based test, the question "what is the main purpose of the article?" is } \\
\text { the most difficult. }\end{array}$ & 2.0303 \\
\hline
\end{tabular}




\begin{tabular}{|l|l|l|l|}
\hline & \multirow{2}{*}{ Q8 } & $\begin{array}{l}\text { In the computer-based test, the question "what is the main purpose of the } \\
\text { article?"is the most difficult }\end{array}$ & 2.5152 \\
\hline \multirow{2}{*}{ Pair 3 } & Q3 & $\begin{array}{l}\text { In the paper-based test, the questions asking when, why, and who are more } \\
\text { difficult than the other questions. }\end{array}$ & 2.5758 \\
\cline { 2 - 3 } & Q6 & $\begin{array}{l}\text { In the computer-based test, the questions asking when, why, and who are more } \\
\text { difficult than the other questions. }\end{array}$ & 2.9394 \\
\hline \multirow{2}{*}{ Pair 4 } & Q5 & In the paper-based test, the vocabulary question is the most difficult. & 2.4848 \\
\cline { 2 - 3 } & Q7 & In the computer-based test, the vocabulary question is the most difficult question. & 2.5455 \\
\hline
\end{tabular}

The first table shows that in pair 1, paper-based test is more difficult to read. In pair 2, in computerbased test, the question "what is the main purpose of the article?" is the most difficult question. In pair 3, in computer-based test, the question asking when, why, and who are the most difficult question. In pair 4 , in computer-based test, the vocabulary question is the most difficult.

Sometimes the questions in paper-based test are difficult to read because the printing quality is not good. Sometimes the pictures and the fonts cannot be read because of the photocopy result. Nevertheless, PBT is easier to do practically than CBT.

Table 2: Pair Sample Test Part II The Students' Perception Towards Hypertext

\begin{tabular}{|c|c|l|c|}
\hline Pair & Q & Statement & Mean \\
\hline \multirow{2}{*}{1} & Q11 & It is easier to do the reading comprehension questions on paper. & 3.6667 \\
\cline { 2 - 4 } & Q12 & It is easier to do the reading comprehension questions on computer screen. & 2.8788 \\
\hline 2 & Q13 & If I have the choice, I would prefer to read articles printed on paper. & 3.5455 \\
\cline { 2 - 4 } & Q14 & If I have the choice, I would prefer to read articles on computer screens. & 3.0000 \\
\hline \multirow{2}{*}{3} & Q19 & I like to read articles on computer screens. & 3.2424 \\
\cline { 2 - 4 } & Q20 & I like to read articles on paper. & 3.7576 \\
\hline
\end{tabular}

The second table devotes that it is easier to answer reading comprehension questions on paper. The students also would prefer to read articles/texts printed on paper. It is in line with the result from the study undertaken by Tseng (2008) who found out that the students performed better in doing tests on printed paper than on computer test.

\subsection{Positive and Negative Sides of the Tests}

The interview results highly indicate that the students prefer paper-based test. They reported some negative sided of using computer to do the examination. First, they need extra time to get used to operate the computers which indeed cannot guarantee they will pass the examination. They think that using CBT will create confusion among them. The schools which have conducted CBT in the previous year might understand better than those who have not. Second, the computer operation really relies on particular circumstance as like the electricity and internet to run CBT. It is more likely that the computer can be slow down anytime. If this happens, it might ruin the students' concentration in doing their national examination. Third, when the electricity goes out, it can be very disappointing for the students who are working on the examination because their works will be disrupted. Fifth, if the students stay on the computer, it is possible to damage their eyes in terms of health point of view. Finally, because the supporting facilities are limited, the examination will usually be divided into several sessions in a day, and its implementation will take time up to six days. It sometimes makes students more saturated in learning because the schedule of the test is longer than usual. Meanwhile, students working with PBT might have finished.

The positive sides of CBT are less-time to work on it, practical to answer, and more secured because it is not easily torn and soiled like using a paper test. Moreover, The students will also be having more experiences in using technology. The system is also less complicated because the students will not be required to bring any writing tools such as pencils, erasers, a ruler. Furthermore, the result will be announced after doing the test.

While, for the positive sides of PBT, the students point out that they prefer to use PBT system because they can read items more detail. Additionally, the examination only lasted for three or four 
days with one subject in a day. Moreover, it is a scribbling booklet, students' eyes might be more comfortable, it can save temporary answer by marking questions or answers in advance before deciding to fill the correct answers.

However, there are some negative sides of PBT. First, the answer sheet could be easily torn. Second, it is time-consuming, especially when the teachers check the students answer. Third, it might use up more paper material if students cause some problems with their answer sheets. Additionally, the students might be easy to cheat with their friends.

Based on the above discussions, Noyes and Garland (2008, p. 1371) also conclude that "the achievement of equivalence in computer and paper-based tasks create a difficult problem and there will always be some tasks where there is not possible".

\section{Conclusions}

Computer-based test is a test conducted by using a computer. Paper-based test is a common test which uses paper and pencil/pen. In this study, the authors can conclude that students in senior high school of Kendari prefer paper-based test for the national examination. They should practice more to do the questions in CBT. Teachers should motivate the students and make them get used to CBT to face the national examination.

\section{References}

Al-amri, S. (2007). Computer-based vs. Paper-based Testing : Does the test administration mode matter? BAAL Conference.

Bates, A. W. (2005). Technology, E-learning and Distance Education D. K. a. A. Tait. New York, Routledge.

Candrlic, S., M. A. Katic, et al. (2014). Online vs. Paper-based Testing : A Comparison of the Test Results. MIPRO 2014.

Coffman, T. (2009). Engaging Students Through Inquiry-Oriented Learning and Technology. United States of America, Rowman \& Littlefield Education

DeSouza, E. and M. Fleming (2003). A Comparison of In-Class and Online Quizzes on Student Examination Performance. Journal of Computing in Higher Education. 14(2): 121-134.

Ghaderi, M. (2014). Comparing Between Computer based Test and Paper-and Pencil based Tests. International Journal of Education \& Literacy Studies. 2(4).

Gordon, A. M. (2015). Paper based Testing vs. Mobile Device Based Testing in an EFL Environment : Whats' the Difference?. Department of English St. Cloud State University. Master of Arts English : Teaching English as $\mathrm{A}$ Second Language.

Heafner, T. (2004). Using Technology to Motivate Students to Learn Social Studies. Contempory Issues in Technology and Teacher Education. 4(1): 42-53.

Hensley, K. K. (2015). Examinationining the Effects of Paper-based and Computer-based Modes of Assessment on Mathematics Curriculum-based Measurement. Doctor of Philosophy degree in Teaching and Learning (Special Education) in the Graduate College. Lowa City, The University of lowa.

Jamil, M., T. R. H., et al. (2012). Computer-based-VS Paper-based Examinationinations: Perceptions of University Teachers. The Turkish Online Journal of Educational Technology. 11(4).

Noyes, J. M. and K. J. Garland (2008). Computer- vs. Paper-Tasks: Are They Equivalent?. Ergonomics. 51(9): $1352-1375$.

O'Donoghue, J., G. Singh, et al. (2004). A comparison of the Advantages and Disadvantages of IT based Education and the Implications upon Students. Interactive Educational Multimedia. 9: 63-76.

Tseng, M. (2008). The Difficulties that EFL Learners Have with Reading Text on the Web. The Internet TESL. XIV(2).

Tseng, M. (2010). Factors that Influence Online Reading : An Investigation into EFL Students' Perceptio. The Reading Matrix. 10(1).

Zajacova, A., S. M. Lynch, et al. (2005). Self-Efficacy, Stressm and Academic Success in College. Research in Higher Education. 46(6).

Zhao, L. (2016). Motivation in Chinese Children's English Teaching. Open Journal of Social Sciences 4: 185188. 